\title{
A Novel Integrated Approach for Green Supplier Selection with Interval-Valued Intuitionistic Uncertain Linguistic Information: A Case Study in the Agri-Food Industry
}

\author{
Hua Shi ${ }^{1}$, Mei-Yun Quan ${ }^{1}$, Hu-Chen Liu ${ }^{1,2, *}$ and Chun-Yan Duan ${ }^{2,3}$ \\ 1 School of Management, Shanghai University, Shanghai 200444, China; huashi@shu.edu.cn (H.S.); \\ quanmeiyun@foxmail.com (M.-Y.Q.) \\ 2 School of Economics and Management, Tongji University, Shanghai 200092, China; \\ duanchunyan@tongji.edu.cn \\ 3 Department of Industrial Engineering, University of Arkansas, Fayetteville, AR 72701, USA \\ * Correspondence: huchenliu@shu.edu.cn
}

Received: 2 February 2018; Accepted: 5 March 2018; Published: 7 March 2018

\begin{abstract}
With strengthening global consciousness of environmental protection, green supply chain management plays an increasingly important role in modern enterprise production operation management. A critical means to implement green supply chain management is incorporating environmental requirements into the supplier selection practices. In this paper, we put forward a novel integrated approach by using interval-valued intuitionistic uncertain linguistic sets (IVIULSs) and grey relational analysis (GRA)-technique for order preference by similarity to ideal solution (TOPSIS) method for the evaluation and selection of green suppliers. First, various qualitative assessments of alternatives provided by decision makers are described by the IVIULSs. Then, the GRA-TOPSIS method is extended and employed to prioritize the alternative suppliers. The proposed model can handle the uncertainty and fuzziness of decision makers' subjective evaluations more easily and get a more realistic and accurate ranking of green suppliers. Finally, an illustrative example in the agri-food industry is presented to verify the proposed green supplier selection model and demonstrate its practicality and effectiveness.
\end{abstract}

Keywords: supply chain management; green supplier selection; interval-valued intuitionistic uncertain linguistic set; GRA-TOPSIS method; agri-food industry

\section{Introduction}

In recent years, public concerns on environmental issues and sustainable development have increased greatly throughout the world [1]. As a result, many business organizations have modified their supply chain activities to reduce negative environmental impacts and enhance sustainability levels [2-4]. Nowadays, green supply chain management (GSCM) has become more prominent than ever before, because the competitiveness of a company is strongly dependent on the performance of its supply chain $[5,6]$. GSCM, as a new management mode to pursue both economic benefits and environment sustainable development, is the management of the flows of funds, information, and products between and among all stages of the supply chain by taking into account the goals from the economic, environmental and social dimensions of sustainable development derived from customer and stakeholder requirements $[7,8]$. The GSCM literature has focused on aiding existing organizations enhance their environmental performance through acquiring certifications or introducing green practices $[9,10]$. GSCM comprises all the activities related to the transformation and flow of goods and services, such as green product design, green supplier evaluation, green production, green 
packaging and transportation, green marketing and resource recycling. Among them, green supplier selection is the essential core, which directly impacts the compatibility of a supply chain and the environmental performance of a manufacturer [11]. Therefore, selection of the optimal green supplier is a key strategic decision in the management of green supply chain, which needs to be explored methodically to implement green initiatives in supply chains [12-14].

Generally, there are two main issues in green supplier selection, which are the evaluation of suppliers and the prioritization of suppliers. In many real situations, due to the complexity of green supplier selection problems, decision makers feel more confident to express their judgements using linguistic descriptors rather than in the form of numerical values [11,13]. Moreover, due to information insufficiency or professional restriction, experts may have difficulties in giving their assessments by simple linguistic terms. Instead, they often doubt among different linguistic terms or require complex linguistic expressions to represent their opinions accurately $[15,16]$. Recently, the definition of interval-valued intuitionistic uncertain linguistic sets (IVIULSs), a combination of uncertain linguistic variables $[17,18]$ and interval-valued intuitionistic fuzzy sets $[19,20]$, was proposed by Liu [21] for handling the ambiguity and uncertainty of decision makers' subjective assessments. The basic feature of the IVIULSs is that the linguistic variable, membership degree and non-membership degree of each element in the given set are presented by interval ranges rather than crisp numbers. Owing to its characteristics and capacities, the IVIULSs have been widely utilized by researchers in various areas, including design pattern evaluation of the micro-air vehicle [22], performance management of sport grounds [23], enterprises knowledge management [24], new rural developing level evaluation [25], and investment decision making [26,27]. Therefore, the theory of IVIULSs is of great value in managing the diversity and uncertainty of decision makers' linguistic assessments in the green supplier selection.

On the other hand, many economic and environmental criteria should be considered during the green supplier selection process. The economic factors include price, quality, delivery, flexibility, and so on $[10,28,29]$; the environmental factors comprise green image, green competencies, reverse logistics, green packaging, and so on $[8,11,28]$. Thus, green supplier selection is a complicated multi-criteria decision making (MCDM) problem and MCDM methods have been recognized as a meritorious tool for evaluating the performance of green suppliers under conflicting criteria. Grey relational analysis (GRA), as one of well-known MCDM methods, is a multi-factor analysis tool to indicate and measure the similarity in order to analyze uncertain relations between alternative series and the reference series [30]. The advantage of the GRA method is that it can deal with complex real-world problems marked by vague, incomplete and inaccurate information [31-33]. Besides, technique for order preference by similarity to ideal solution (TOPSIS) is a typical MCDM method proposed by Hwang and Yoon [34], which has been extensively applied in a variety of fields. The basic principle of the TOPSIS method is that the most satisfactory alternative should have the nearest distance to the positive ideal solution (PIS) and the farthest distance to the negative ideal solution (NIS) [35-37]. In order to combine the desired properties of the two methods, the GRA has been integrated with TOPSIS, called as GRA-TOPSIS, for solving MCDM problems recently [38-41]. Therefore, it is expected to utilize the GRA-TOPSIS method to derive a more precise ranking of alternatives in the green supplier selection.

Based on the analyses discussed above, the objective of this research is to propose a novel integrated approach combining IVIULSs and the GRA-TOPSIS method for addressing green supplier evaluation problems with uncertain linguistic information. The main contributions of this research are as follows: Firstly, the IVIULSs are utilized to deal with various uncertainties in the performance assessments of decision makers on alternative suppliers. Secondly, the GRA-TOPSIS method is extended to prioritize and compare green suppliers by simultaneously computing the grey relational degree to PIS and NIS. Thirdly, an illustrate example from the agri-food industry is presented to elaborate the application and effectiveness of the proposed green supplier selection approach. The new integrated approach has a good reflection of subjective assessments and objective information under 
uncertain information environment. It is more realistic and practical to select and evaluate the most efficient sustainable supplier from a set of alternatives in the supply chain.

The remaining part of this paper is structured as follows. Section 2 provides a review of the existing literature relevant to this study. Section 3 briefly introduces the basic concepts and definitions of IVIULSs. In Section 4, we develop the integrated green supplier selection framework based on IVIULSs and GRA-TOPSIS method. In Section 5, a practical example of agri-food industry is given to confirm the practicability and effectiveness of the proposed approach. Finally, we summarize concluding remarks and give future research suggestions in Section 6.

\section{Literature Review}

\subsection{Green Supplier Selection Methods}

In the literature, the number of studies on green supplier selection has increased considerably in recent years. For dealing with green supplier selection problems, a variety of MCDM methods have been utilized by researchers. For example, Awasthi et al. [42] proposed an integrated fuzzy analytic hierarchy process (AHP)-VIKOR (in Serbian: ViseKriterijumska Optimizacija I Kompromisno Resenje) based framework for sustainable global supplier selection considering risks that arise from a focal company's sub-suppliers. Luthra et al. [6] presented an integrated AHP-VIKOR based approach for the evaluation and selection of sustainable suppliers in an Indian automobile industry. Wang et al. [11] put forward an integrated MCDM approach based on cloud model theory and QUALIFLEX (qualitative flexible multiple criteria method) for green supplier selection by considering various environmental requirements and criteria. Qin et al. [7] extended the TODIM (in Portuguese: interactive and multi-criteria decision making) method to solve green supplier selection problems with interval type-2 fuzzy information. Fallahpour et al. [4] combined fuzzy preference programming (FPP) with fuzzy TOPSIS for supplier evaluation in sustainable supply chain management. Yu and Hou [43] utilized a modified multiplicative analytic hierarchy process (MMAHP) method to select the best green supplier for an automobile manufacturing firm. Yazdani et al. [44] reported an integrated model using step-wise weight assessment ratio analysis (SWARA), quality function deployment (QFD), and weighted aggregated sum product assessment (WASPAS) for green supplier selection in the stainless steel industry. Liou et al. [45] proposed a hybrid model combining decision-making trial and evaluation laboratory (DEMATEL)-based analytic network process (ANP) and COmplex PRoportional ASsessment of alternatives with Grey relations (COPRAS-G) for selecting suppliers in green supply chain management. Keshavarz Ghorabaee et al. [14] suggested an extended WASPAS method with interval type-2 fuzzy sets for the multi-criteria group evaluation of green suppliers. In addition, a more detailed literature review and classification of current green supplier selection methods can be seen in [46].

\subsection{Food Supply Chain Management}

Due to the increasing demand for high-quality and nutritious food, stakeholders are more than ever encouraging food processing companies to improve the sustainability performance of their supply chains. Therefore, many studies have been conducted for green supply management in the agri-food industry. For instance, Banaeian et al. [33] applied three fuzzy group decision making methods, including fuzzy TOPSIS, fuzzy VIKOR and fuzzy GRA, to complete the supplier evaluation and selection for a manufacturer of edible vegetable oils and detergents. Govindan et al. [47] applied a preference ranking organization method for enrichment evaluation (PROMETHEE)-based multiple criteria ranking approach to deal with green supplier selection for an India food processing industry. Yazdani et al. [12] presented an integrated approach consisting of DEMATEL, QFD, and COPRAS methods, and applied it for an Iranian dairy company. Tavana et al. [48] developed an integrated sustainable supplier selection model to analyze the case study of a dairy company, in which ANP is integrated with QFD to weight customer requirements and evaluation criteria, and 
multi-objective optimization based on ratio analysis (MOORA) and WASPAS are used to rank suppliers. Shashi et al. [49] investigated the value addition relationships between different parties involved in the food supply chain to improve overall as well as individual benefits of the supply chain players. In Baraki and Kianfar [50], a multi-objective mathematical model was proposed to select suppliers and allocate optimal orders to them in a two-echelon supply chain, including supply and distribution echelons. The efficiency and effectiveness of the proposed model were validated through implementing in a food distribution chain in Iran. In Ravi and Shankar [51], the authors explored the relationships among critical issues of reverse logistics and the dissimilarities among different industrial sectors in implementing common reverse logistics practices. A nationwide survey showed that companies in electronics sector significantly differ from those of other sectors (i.e., auto, paper, and food and beverage processing) in adoption of reverse logistics practices. Shashi et al. [52] provided a literature review focused on the topic of food cold chain management over the last sixteen years to identify state of the art in the literature and define appropriate research questions for future research.

The extensive review of the related literature shows that many researchers had made use of fuzzy set theory to address the uncertainty and fuzziness during the green supplier selection process. However, the fuzzy sets only consider the preference degrees of the decision maker, but cannot address the non-preference degrees of the decision maker. On the other hand, a lot of MCDM methods have been employed to rank and select the most preferred green supplier. But no or few prior studies have combined the concepts of two or more MCDM methods to obtain the ranking orders of green supplier with respect to the determined criteria. With these issues, this paper aims to propose a novel integrated approach by using IVIULSs and the GRA-TOPSIS method for the evaluation and selection of green suppliers. The proposed model is highly effective and useful for green supplier selection problems, because it can denote decision makers' quantitative and qualitative references simultaneously and has the ability to acquire a more precise ranking result by combining the advantages of GRA and TOPSIS methods. Furthermore, a real case example of the agri-food industry is discussed in this paper to reveal the application of the proposed green supplier selection approach.

\section{Basic Concepts}

In this section, the basic concepts and operations of IVIULSs that will be used in our proposed approach are introduced.

Definition 1. [21]. Let X be a given domain and $\widetilde{s}_{x} \in \widetilde{S}$. Then the IVIULS can be defined as

$$
\widetilde{A}=\left\{<x\left(\widetilde{s}_{x}, \widetilde{u}_{\widetilde{A}}(x), \widetilde{v}_{\widetilde{A}}(x)\right)>\right\},
$$

where $\widetilde{s}_{x}=\left[s_{\theta(x)}, s_{\tau(x)}\right]$ is a uncertain linguistic variable, $\theta(x)$ and $\tau(x)$ are the subscripts of the lower limit and upper limit to $\widetilde{s}_{x}$. The intervals $\widetilde{u}_{\widetilde{A}}: X \rightarrow D[0,1]$ and $\widetilde{v}_{\widetilde{A}}: X \rightarrow D[0,1]$ denote respectively the membership degree and non-membership degree of the element $x$ to the uncertain linguistic variable $\widetilde{s}_{x}$ with the condition that $0 \leq \sup \left(\widetilde{u}_{\widetilde{A}}(x)\right)+\sup \left(\widetilde{v}_{\widetilde{A}}(x)\right) \leq 1, x \in X$.

For any element $x \in X, \widetilde{u}_{\widetilde{A}}(x)$ and $\widetilde{v}_{\widetilde{A}}(x)$ are closed intervals and their lower points and upper points are denoted as $u_{\widetilde{A}}^{L}(x), u_{\widetilde{A}}^{U}(x), v_{\widetilde{A}}^{L}(x)$ and $v_{\widetilde{A}}^{U}(x)$. Then, $\widetilde{A}$ can be represented by

$$
\widetilde{A}=\left\{\left\langle x\left(\left[s_{\theta(x)}, s_{\tau(x)}\right],\left[u_{\widetilde{A}}^{L}(x), u_{\widetilde{A}}^{U}(x)\right],\left[v_{\widetilde{A}}^{L}(x), v_{\widetilde{A}}^{U}(x)\right]\right)\right\rangle \mid x \in X\right\},
$$

where $s_{\theta(x)}, s_{\tau(x)} \in S, 0 \leq u_{\widetilde{\widetilde{A}}}^{U}(x)+v_{\widetilde{A}}^{U}(x) \leq 1, u_{\widetilde{A}}^{L}(x) \geq 0$ and $v_{\widetilde{A}}^{L}(x) \geq 0$.

For any element $x \in X$, the hesitation interval of the element $x$ to the uncertain linguistic variable $\widetilde{s}_{x}=\left[s_{\theta(x)}, s_{\tau(x)}\right]$ is computed as:

$$
\widetilde{\pi}_{\widetilde{A}}(x)=\left[\pi_{\widetilde{A}}^{L}(x), \pi_{\widetilde{A}}^{U}(x)\right]=\left[1-u_{\widetilde{A}}^{U}(x)-v_{\widetilde{A}}^{U}(x), 1-u_{\widetilde{A}}^{L}(x)-v_{\widetilde{A}}^{L}(x)\right] .
$$


Definition 2. [22] Suppose $\widetilde{A}=\left\{\left\langle x\left(\left[s_{\theta(x)}, s_{\tau(x)}\right],\left[u_{\widetilde{A}}^{L}(x), u_{\widetilde{A}}^{U}(x)\right],\left[v_{\widetilde{A}}^{L}(x), v_{\widetilde{A}}^{U}(x)\right]\right)\right\rangle \mid x \in X\right\}$ is an IVIULS. Then, the 6-tuple $\left\langle\left[s_{\theta(x)}, s_{\tau(x)}\right],\left[u_{\widetilde{A}}^{L}(x), u_{\widetilde{A}}^{U}(x)\right],\left[v_{\widetilde{A}}^{L}(x), v_{\widetilde{A}}^{U}(x)\right]\right\rangle$ is called an interval-valued intuitionistic uncertain linguistic number (IVIULN), and $\widetilde{A}$ can also be regarded as a collection of the IVIULNs, i.e., $\widetilde{A}=\left\{\left\langle\left[s_{\theta(x)}, s_{\tau(x)}\right],\left[u_{\widetilde{A}}^{L}(x), u_{\widetilde{A}}^{U}(x)\right],\left[v_{\widetilde{A}}^{L}(x), v_{\widetilde{A}}^{U}(x)\right]\right\rangle \mid x \in X\right\}$.

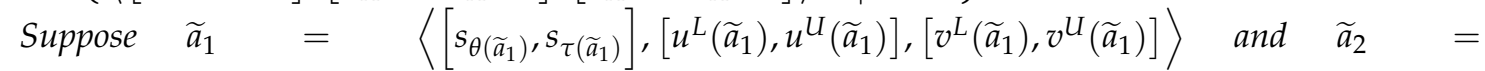
$\left\langle\left[s_{\theta\left(\widetilde{a}_{2}\right)}, s_{\tau\left(\widetilde{a}_{2}\right)}\right],\left[u^{L}\left(\widetilde{a}_{2}\right), u^{U}\left(\widetilde{a}_{2}\right)\right],\left[v^{L}\left(\widetilde{a}_{2}\right), v^{U}\left(\widetilde{a}_{2}\right)\right]\right\rangle$ are two IVIULNs and $\lambda \geq 0$, the basic operations about $\widetilde{a}_{1}$ and $\widetilde{a}_{2}$ are defined as follows $[21,25]$ :

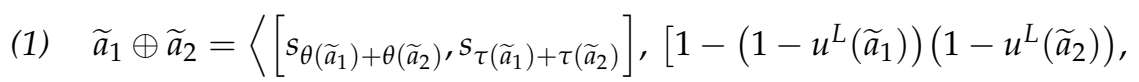

$$
\left.\left.1-\left(1-u^{U}\left(\widetilde{a}_{1}\right)\right)\left(1-u^{U}\left(\widetilde{a}_{2}\right)\right)\right],\left[v^{L}\left(\widetilde{a}_{1}\right) v^{L}\left(\widetilde{a}_{2}\right), v^{U}\left(\widetilde{a}_{1}\right) v^{U}\left(\widetilde{a}_{2}\right)\right]\right\rangle ;
$$

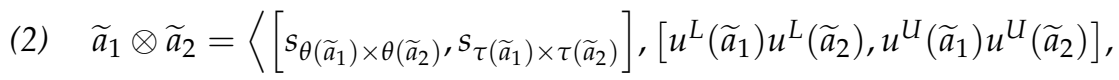

$$
\left.\left[1-\left(1-v^{L}\left(\widetilde{a}_{1}\right)\right)\left(1-v^{L}\left(\widetilde{a}_{2}\right)\right), 1-\left(1-v^{U}\left(\widetilde{a}_{1}\right)\right)\left(1-v^{U}\left(\widetilde{a}_{2}\right)\right)\right]\right\rangle ;
$$

(3) $\lambda \widetilde{a}_{1}=\left\langle\left[s_{\lambda \times \theta\left(\widetilde{a}_{1}\right)}, s_{\lambda \times \tau\left(\widetilde{a}_{1}\right)}\right],\left[1-\left(1-u^{L}\left(\widetilde{a}_{1}\right)\right)^{\lambda}, 1-\left(1-u^{U}\left(\widetilde{a}_{1}\right)\right)^{\lambda}\right],\left[\left(v^{L}\left(\widetilde{a}_{1}\right)\right)^{\lambda},\left(v^{U}\left(\widetilde{a}_{1}\right)\right)^{\lambda}\right]\right\rangle$;

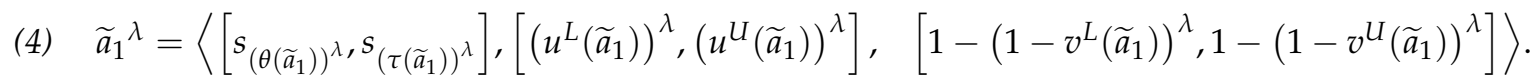

To compare IVIULNs, the expected value and the accuracy degree of an IVIULN are defined as below.

Definition 3. [21]. $\widetilde{a}_{1}=\left\langle\left[s_{\theta(\widetilde{a})}, s_{\tau(\widetilde{a})}\right],\left[u^{L}(\widetilde{a}), u^{U}(\widetilde{a})\right],\left[v^{L}(\widetilde{a}), v^{U}(\widetilde{a})\right]\right\rangle$ is an IVIULN. The expected value of $\widetilde{a}$ is expressed as

$$
\begin{gathered}
E(\widetilde{a})=\frac{1}{2}\left(\frac{u^{L}(\widetilde{a})+u^{U}(\widetilde{a})}{2}+1-\left(\frac{v^{L}(\widetilde{a})+v^{U}(\widetilde{a})}{2}\right)\right) \times s_{(\theta(\widetilde{a})+\tau(\widetilde{a})) / 2} \\
=s_{\left.(\theta(\widetilde{a})+\tau(\widetilde{a})) \times\left(u^{L}(\widetilde{a})\right)+u^{U}(\widetilde{a})+2-v^{L}(\widetilde{a})-v^{U}(\widetilde{a})\right) / 8^{\prime}}
\end{gathered}
$$

and the accuracy degree of $\widetilde{a}$ is denoted by

$$
\begin{aligned}
T(\widetilde{a})= & s_{(\theta(\widetilde{a})+\tau(\widetilde{a})) / 2} \times\left(\frac{u^{L}(\widetilde{a})+u^{U}(\widetilde{a})}{2}+\frac{v^{L}(\widetilde{a})+v^{U}(\widetilde{a})}{2}\right) \\
& =s_{\left(u^{L}(\widetilde{a})+u^{U}(\widetilde{a})+v^{L}(\widetilde{a})+v^{U}(\widetilde{a})\right) \times(\theta(\widetilde{a})+\tau(\widetilde{a})) / 4 .}
\end{aligned}
$$

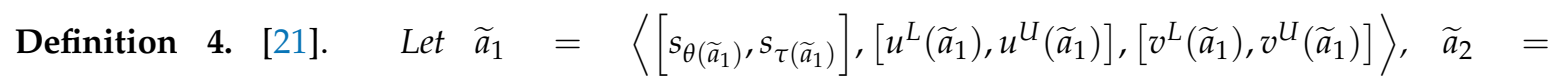

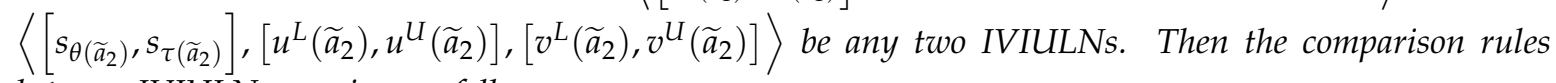
between IVIULNs are given as follows:

(1) If $E\left(\widetilde{a}_{1}\right)>E\left(\widetilde{a}_{2}\right)$, then $\widetilde{a}_{1}>\widetilde{a}_{2}$;

(2) If $E\left(\widetilde{a}_{1}\right)=E\left(\widetilde{a}_{2}\right)$, then

(a) If $T\left(\widetilde{a}_{1}\right)>T\left(\widetilde{a}_{2}\right)$, then $\widetilde{a}_{1}>\widetilde{a}_{2}$;

(b) If $T\left(\widetilde{a}_{1}\right)=T\left(\widetilde{a}_{2}\right)$, then $\widetilde{a}_{1}=\widetilde{a}_{2}$. 
Definition 5. [21]. Let $\widetilde{a}_{i}=\left\langle\left[s_{\theta\left(\widetilde{a}_{i}\right)}, s_{\tau\left(\widetilde{a}_{i}\right)}\right),\left[u^{L}\left(\widetilde{a}_{i}\right), u^{U}\left(\widetilde{a}_{i}\right)\right],\left[v^{L}\left(\widetilde{a}_{i}\right), v^{U}\left(\widetilde{a}_{i}\right)\right]\right\rangle(i=1,2, \ldots, n)$ be a collection of IVIULNs. Then, interval-valued intuitionistic uncertain linguistic weighted geometric average (IVIULWGA) operator is defined as:

$$
\begin{aligned}
& \text { IVIULWGA }_{w} \quad\left(\widetilde{a}_{1}, \widetilde{a}_{2}, \ldots, \widetilde{a}_{n}\right)=\bigotimes_{i=1}^{n}\left(\widetilde{a}_{i}\right)^{w_{i}} \\
& =\left\langle\left[\sum_{i=1}^{n}\left(\theta\left(\widetilde{a}_{i}\right)\right)^{w_{i}}{ }^{\prime} \sum_{i=1}^{n}\left(\theta\left(\widetilde{a}_{i}\right)\right)^{w_{i}}\right],\left[\prod_{i=1}^{n}\left(u^{L}\left(\widetilde{a}_{i}\right)\right)^{w_{i}}, \prod_{i=1}^{n}\left(u^{U}\left(\widetilde{a}_{i}\right)\right)^{w_{i}}\right],\right. \\
& \left.\left[1-\prod_{i=1}^{n}\left(1-v^{L}\left(\widetilde{a}_{i}\right)\right)^{w_{i}}, 1-\prod_{i=1}^{n}\left(1-v^{U}\left(\widetilde{a}_{i}\right)\right)^{w_{i}}\right]\right\rangle,
\end{aligned}
$$

where $w=\left(w_{1}, w_{2}, \ldots, w_{n}\right)^{T}$ is the weight vector of $\widetilde{a}_{i}(i=1,2, \ldots, n)$ with the condition $w_{i} \in[0,1]$ and $\sum_{i=1}^{n} w_{i}=1$

Definition 6. Let $\widetilde{a}_{1}=\left\langle\left[s_{\theta\left(\widetilde{a}_{1}\right)}, s_{\tau\left(\widetilde{a}_{1}\right)}\right],\left[u^{L}\left(\widetilde{a}_{1}\right), u^{U}\left(\widetilde{a}_{1}\right)\right],\left[v^{L}\left(\widetilde{a}_{1}\right), v^{U}\left(\widetilde{a}_{1}\right)\right]\right\rangle$ and $\widetilde{a}_{2}=$

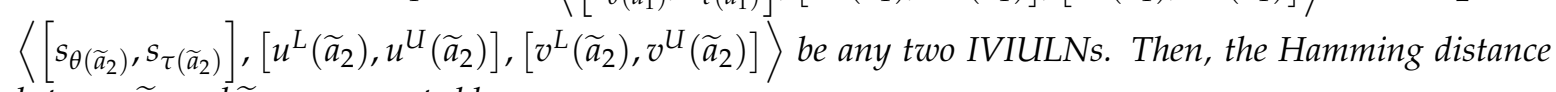
between $\widetilde{a}_{1}$ and $\widetilde{a}_{2}$ are computed by

$$
d\left(\widetilde{a}_{1}, \widetilde{a}_{2}\right)=\frac{1}{6}\left(\begin{array}{r}
\left(\left|\theta\left(\widetilde{a}_{1}\right)-\theta\left(\widetilde{a}_{2}\right)\right|+\left|\tau\left(\widetilde{a}_{1}\right)-\tau\left(\widetilde{a}_{2}\right)\right|\right) / 9+\left|u^{L}\left(\widetilde{a}_{1}\right)-u^{L}\left(\widetilde{a}_{2}\right)\right| \\
+\left|u^{U}\left(\widetilde{a}_{1}\right)-u^{U}\left(\widetilde{a}_{2}\right)\right|+\left|v^{L}\left(\widetilde{a}_{1}\right)-v^{L}\left(\widetilde{a}_{2}\right)\right|+\left|v^{U}\left(\widetilde{a}_{1}\right)-v^{U}\left(\widetilde{a}_{2}\right)\right|
\end{array}\right) .
$$

\section{The Proposed Green Supplier Selection Approach}

In this section, we put forward a novel integrated approach based on IVIULSs and GRA-TOPSIS method to evaluate and select the optimal green supplier. In the proposed green supplier selection model, IVIULSs are used to assess the green performance of suppliers under economic and environmental criteria, and the GRA-TOPSIS method is utilized for ranking the alternative green suppliers. The flowchart of the proposed approach for the selection of green suppliers is shown in Figure 1.

Suppose that a green supplier selection problem has $m$ alternatives $A_{i}(i=1,2, \ldots, m)$, $n$ evaluation criteria $C_{j}(j=1,2, \ldots, n)$ and $l$ decision makers $\operatorname{DM}_{k}(k=1,2, \ldots, l)$. The weight of $\mathrm{DM}_{k}$ is given as $\lambda_{k}$ which satisfies $\lambda_{k}>0$ and $\sum_{k=1}^{l} \lambda_{k}=1$; it reflect the relative significance of the decision maker in the process of green supplier selection. Suppose $\widetilde{P}^{k}=\left[\widetilde{p}_{i j}^{k}\right]_{m \times n}$ is the evaluation matrix by the $k$ th decision maker for alternative $A_{i}$ with regard to criterion $C_{j}$, and $\tilde{p}_{i j}^{k}=\left\langle\left[s_{a_{i j k}^{L}}, s_{a_{i j k}}\right],\left[u_{i j k}^{L}, u_{i j k}^{U}\right],\left[v_{i j k}^{L}, v_{i j k}^{U}\right]\right\rangle$ is the IVIULN given by $\mathrm{DM}_{k}$ based on the linguistic term set $S=\left\{s_{0}, s_{1}, \ldots, s_{g}\right\}$. Let $\widetilde{w}^{k}=\left(\widetilde{w}_{1}^{k}, \widetilde{w}_{2}^{k}, \ldots, \widetilde{w}_{n}^{k}\right)$ be the weight vector of criteria provided by $\mathrm{DM}_{k}$, where $\widetilde{w}_{j}^{k}=\left\langle\left[s_{a_{j k}^{L}}^{\prime}, s_{a_{j k}^{\prime}}^{\prime}\right],\left[u_{j k}^{\prime L}, u_{j k}^{\prime U}\right],\left[v_{j k}^{\prime L}, v_{j k}^{\prime U}\right]\right\rangle$ is the IVIULN assigned to the weight of $C_{j}$ by using the linguistic term set $S_{w}=\left\{s_{0}^{\prime}, s_{1}^{\prime}, \ldots, s_{h}^{\prime}\right\}$. Based on these notations and assumptions, the procedure of the proposed green supplier selection model is expressed as the following steps.

Step 1: Construct the collective evaluation matrix $\widetilde{P}$ 
First, we use the IVIULWGA operator to aggregate the individual evaluation matrices $\widetilde{P}^{k}(k=1,2, \ldots, l)$ to establish the collective evaluation matrix $\widetilde{P}=\left[\widetilde{p}_{i j}\right]_{m \times n^{\prime}}$, where

$$
\widetilde{p}_{i j}=\operatorname{IVIULWGA}\left(\widetilde{p}_{i j}^{1}, \widetilde{p}_{i j}^{2}, \ldots, \widetilde{p}_{i j}^{l}\right)=\bigotimes_{k=1}^{l}\left(\widetilde{p}_{i j}^{k}\right)^{\lambda_{k}},
$$

where $\widetilde{p}_{i j}=\left\langle\left[s_{a_{i j}^{L}}, s_{a_{i j}^{U}}\right],\left[u_{i j}^{L}, u_{i j}^{U}\right],\left[v_{i j}^{L}, v_{i j}^{U}\right]\right\rangle$ is the collective assessment of alternative $A_{i}$ with

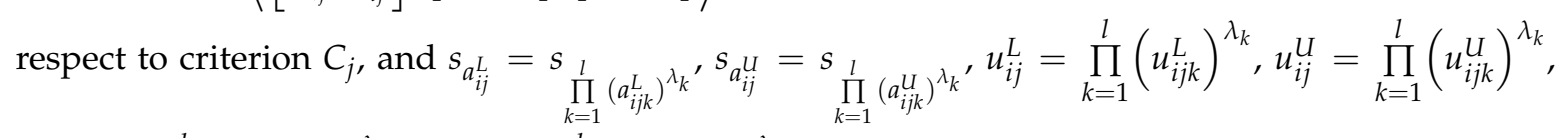
$v_{i j}^{L}=1-\prod_{k=1}^{l}\left(1-v_{i j k}^{L}\right)^{\lambda_{k}}, v_{i j}^{U}=1-\prod_{k=1}^{l}\left(1-v_{i j k}^{U}\right)^{\lambda_{k}}$.

Step 2: Acquire the collective criteria weight vector $\widetilde{w}$

Each decision maker has his/her own experience, which may result in different assessments on the criteria weights. The collective weight vector of criteria, $\widetilde{w}=\left(\widetilde{w}_{1}, \widetilde{w}_{2}, \ldots, \widetilde{w}_{n}\right)$, can also be computed by making use of the IVIULWGA operator, i.e.,

$$
\left.\widetilde{w}_{j}=\operatorname{IVIULWGA}\left(\widetilde{w}_{j}^{1}, \widetilde{w}_{j}^{2}, \ldots, \widetilde{w}_{j}^{l}\right)={\underset{k=1}{l}}_{\left(\widetilde{w}_{j}^{k}\right.}\right)^{\lambda_{k}},
$$

where $\widetilde{w}_{j}=\left\langle\left[s_{a_{j}^{L}}^{\prime}, s_{a_{j}^{U}}^{\prime}\right],\left[u_{j}^{\prime L}, u_{j}^{\prime U}\right],\left[v_{j}^{\prime L} v_{j}^{\prime L}, v_{j}^{\prime U}\right]\right\rangle$ is the aggregated weight of $C_{j}$, and $s_{a_{j}^{L}}^{\prime}=s_{\prod_{k=1}^{\prime}\left(a_{j k}^{L}\right)^{\lambda_{k}}{ }^{\prime}}$ $s_{a_{j}^{U}}^{\prime}=s_{\prod_{k=1}^{\prime}\left(a_{j k}^{U}\right)^{\lambda_{k}}{ }^{\prime}} u_{j}^{\prime L}=\prod_{k=1}^{l}\left(u_{j k}^{\prime L}\right)^{\lambda_{k}}, u_{j}^{\prime U}=\prod_{k=1}^{l}\left(u_{j k}^{\prime U}\right)^{\lambda_{k}}, v_{j}^{\prime L}=1-\prod_{k=1}^{l}\left(1-v_{j k}^{\prime L}\right)^{\lambda_{k}}$, $v_{j}^{U}=1-\prod_{k=1}^{l}\left(1-v_{j k}^{\prime U}\right)^{\lambda_{k}}$.

Step 3: Determine the PIS and the NIS

The PIS and the NIS represent the most desirable alternative and the least desirable alternative, respectively. The sets of beneficial criteria and cost criteria are denoted as $J_{1}$ and $J_{2}$. Then, the PIS and the NIS can be defined by the following equations:

$$
\begin{gathered}
\widetilde{p}^{+}=\left(\widetilde{p}_{1}^{+}, \widetilde{p}_{2}^{+}, \ldots, \widetilde{p}_{n}^{+}\right), \\
\widetilde{p}^{-}=\left(\widetilde{p}_{1}^{-}, \widetilde{p}_{2}^{-}, \ldots, \widetilde{p}_{n}^{-}\right) . \\
\text {Suppose } \widetilde{p}_{j}^{+}=\left\langle\left[s_{a_{j}^{L+}}, s_{a_{j}^{U+}}\right],\left[u_{j}^{L+}, u_{j}^{U+}\right],\left[v_{j}^{L+}, v_{j}^{U+}\right]\right\rangle \text { for } j=1,2, \ldots, n \text {. Then, we have } \\
s_{a_{j}^{L+}}=\left(\left(\max _{i} s_{a_{i j}^{L}} \mid j \in J_{1}\right),\left(\min _{i} s_{a_{i j}^{L}} \mid j \in J_{2}\right)\right), \\
s_{a_{j}^{U+}}=\left(\left(\max _{i} a_{i j}^{u} \mid j \in J_{1}\right),\left(\min _{i} s_{a_{i j}^{U}} \mid j \in J_{2}\right)\right), \\
u_{j}^{L+}=\left(\left(\max _{i} u_{i j}^{L} \mid j \in J_{1}\right),\left(\min _{i} u_{i j}^{L} \mid j \in J_{2}\right)\right), \\
u_{j}^{U+}=\left(\left(\max _{i} u_{i j}^{U} \mid j \in J_{1}\right),\left(\min _{i} u_{i j}^{U} \mid j \in J_{2}\right)\right), \\
v_{j}^{L+}=\left(\left(\min _{i} v_{i j}^{L} \mid j \in J_{1}\right),\left(\max _{i} v_{i j}^{L} \mid j \in J_{2}\right)\right),
\end{gathered}
$$




$$
v_{j}^{U+}=\left(\left(\min _{i} v_{i j}^{U} \mid j \in J_{1}\right),\left(\max _{i} v_{i j}^{U} \mid j \in J_{2}\right)\right) .
$$

Suppose $\widetilde{p}_{j}^{-}=\left\langle\left[s_{a_{j}^{L-}}, s_{a_{j}^{U-}}\right],\left[u_{j}^{L-}, u_{j}^{U-}\right],\left[v_{j}^{L-}, v_{j}^{U-}\right]\right\rangle$ for $j=1,2, \ldots, n$. Then, we have

$$
\begin{aligned}
& s_{a_{j}^{L-}}=\left(\left(\min _{i} s_{a_{i j}^{L}} \mid j \in J_{1}\right),\left(\max _{i} a_{a_{i j}^{L}} \mid j \in J_{2}\right)\right), \\
& s_{a_{j}^{U-}}=\left(\left(\min _{i} s_{a_{i j}^{U}} \mid j \in J_{1}\right),\left(\operatorname{maxs}_{i} a_{i j}^{U} \mid j \in J_{2}\right)\right), \\
& u_{j}^{L-}=\left(\left(\min _{i} u_{i j}^{L} \mid j \in J_{1}\right),\left(\max _{i} u_{i j}^{L} \mid j \in J_{2}\right)\right), \\
& u_{j}^{U-}=\left(\left(\min _{i} u_{i j}^{U} \mid j \in J_{1}\right),\left(\max _{i} u_{i j}^{U} \mid j \in J_{2}\right)\right), \\
& v_{j}^{L-}=\left(\left(\max _{i} v_{i j}^{L} \mid j \in J_{1}\right),\left(\min _{i} v_{i j}^{L} \mid j \in J_{2}\right)\right), \\
& v_{j}^{U-}=\left(\left(\max _{i} v_{i j}^{U} \mid j \in J_{1}\right),\left(\min _{i} v_{i j}^{U} \mid j \in J_{2}\right)\right) .
\end{aligned}
$$

Step 4: Calculate the grey relation coefficients to the PIS and the NIS

The PIS and the NIS can be taken as reference sequences and all the alternative green suppliers can be considered as comparative sequences. The grey relation coefficients are used to determine how close $\widetilde{p}_{i j}$ to $\widetilde{p}_{j}^{+}$and $\widetilde{p}_{j}^{-}$. The grey relation coefficients of each criterion of the $m$ green suppliers to the PIS and the NIS can be calculated by

$$
\begin{aligned}
& r_{i j}^{+}=\frac{\operatorname{minmin}_{i} d\left(\widetilde{p}_{i j}, \widetilde{p}_{j}^{+}\right)+\operatorname{maxmax}_{i} \max _{j}\left(\widetilde{p}_{i j}, \widetilde{p}_{j}^{+}\right)}{d\left(\widetilde{p}_{i j}, \widetilde{p}_{j}^{+}\right)+\varsigma \operatorname{maxmax}_{i}\left(\widetilde{p}_{i j}, \widetilde{p}_{j}^{+}\right)}, i=1,2, \ldots, m, \quad j=1,2, \ldots, n, \\
& r_{i j}^{-}=\frac{\operatorname{minmin}_{i}\left(\widetilde{p}_{i j}, \widetilde{p}_{j}^{-}\right)+\varsigma \operatorname{maxmax}_{i} d\left(\widetilde{p}_{i j}, \widetilde{p}_{j}^{-}\right)}{d\left(\widetilde{p}_{i j}, \widetilde{p}_{j}^{-}\right)+\varsigma \operatorname{maxmax}_{i}\left(\widetilde{p}_{i j}, \widetilde{p}_{j}^{-}\right)}, \quad i=1,2, \ldots, m, \quad j=1,2, \ldots, n,
\end{aligned}
$$

where $d\left(\widetilde{p}_{i j}, \widetilde{p}_{j}^{+}\right)$and $d\left(\widetilde{p}_{i j}, \widetilde{p}_{j}^{-}\right)$represent the Hamming distances from $\widetilde{p}_{i j}$ to $\widetilde{p}_{j}^{+}$and $\widetilde{p}_{j}^{-}$, respectively. $\varsigma$ is the distinguishing coefficient, $\varsigma \in[0,1]$; generally, $\varsigma=0.5$ is applied in the real decision-making problems.

As a result, the grey relation coefficient matrices of alternatives to the PIS $R^{+}$and the NIS $R^{-}$can be represented as

$$
\begin{aligned}
R^{+} & =\left[\begin{array}{rrrr}
r_{11}^{+} & r_{12}^{+} & \cdots & r_{1 n}^{+} \\
r_{21}^{+} & r_{22}^{+} & \cdots & r_{2 n}^{+} \\
\vdots & \vdots & \vdots & \vdots \\
r_{m 1}^{+} & r_{m 2}^{+} & \cdots & r_{m n}^{+}
\end{array}\right], \\
R^{-} & =\left[\begin{array}{rrrr}
r_{11}^{-} & r_{12}^{-} & \cdots & r_{1 n}^{-} \\
r_{21}^{-} & r_{22}^{-} & \cdots & r_{2 n}^{-} \\
\vdots & \vdots & \vdots & \vdots \\
r_{m 1}^{-} & r_{m 2}^{-} & \cdots & r_{m n}^{-}
\end{array}\right] .
\end{aligned}
$$


Step 5: Compute the grey relation grades to the PIS and the NIS

This step is to calculate the grey relation grades of the alternative suppliers to the PIS $\widetilde{r}_{i}^{+}$and the NIS $\widetilde{r}_{i}^{-}$by

$$
\begin{aligned}
& \widetilde{r}_{i}^{+}=\widetilde{r}\left(\widetilde{p}_{i}, \widetilde{p}^{+}\right)=\sum_{j=1}^{n} \widetilde{w}_{j} r_{i j}^{+}, \quad i=1,2, \ldots, m, \\
& \widetilde{r}_{i}^{-}=\widetilde{r}\left(\widetilde{p}_{i}, \widetilde{p}^{-}\right)=\sum_{j=1}^{n} \widetilde{w}_{j} r_{i j}^{-}, \quad i=1,2, \ldots, m .
\end{aligned}
$$

Here,

$$
\widetilde{w}_{j} r_{i j}^{+}=\left\langle\left[s_{r_{i j}^{+} a_{j}^{L}}^{\prime}, s_{r_{i j}^{+} a_{j}^{u}}^{\prime}\right],\left[1-\left(1-u_{j}^{\prime L}\right)^{r_{i j}^{+}}, 1-\left(1-u_{j}^{\prime U}\right)^{r_{i j}^{+}}\right],\left[\left(v_{j}^{\prime L}\right)^{r_{i j}^{+}},\left(v_{j}^{\prime L}\right)^{r_{i j}^{+}}\right]\right\rangle .
$$

Then, $\widetilde{r}_{i}^{+}$can be represented by

$$
\begin{aligned}
& \widetilde{r}_{i}^{+}=\left\langle\left[s_{\sum_{j=1}^{\prime} r_{i j}^{+} a_{j}^{L^{\prime}}} s^{\prime} \sum_{j=1}{ }_{n=1} r_{i j}^{+} a_{j}^{U}\right],\left[1-\prod_{j=1}^{n}\left(1-u_{j}^{\prime L}\right)^{r_{i j}^{+}}, 1-\prod_{j=1}^{n}\left(1-u_{j}^{\prime U}\right)^{r_{i j}^{+}}\right],\right. \\
& \left.\left[\prod_{j=1}^{n}\left(v_{j}^{\prime L}\right)^{r_{i j}^{+}}, \prod_{j=1}^{n}\left(v_{j}^{\prime U}\right)^{r_{i j}^{+}}\right]\right\rangle, \quad i=1,2, \ldots, m .
\end{aligned}
$$

In addition, $\widetilde{r}_{i}^{-}$can be calculated as

$$
\begin{gathered}
\widetilde{r}_{i}^{-}=\left\langle\left[{s_{j=1}^{\prime} r_{i j}^{-} a_{j}^{\prime}}_{a_{j=1}^{\prime}} \sum_{\sum_{j=1}^{n}} r_{i j}^{-} a_{j}^{U}\right],\left[1-\prod_{j=1}^{n}\left(1-u_{j}^{\prime L}\right)^{r_{i j}^{-}}, 1-\prod_{j=1}^{n}\left(1-u_{j}^{\prime U}\right)^{r_{i j}^{-}}\right],\right. \\
\left.\left[\prod_{j=1}^{n}\left(v_{j}^{\prime L}\right)^{r_{i j}^{-}}, \prod_{j=1}^{n}\left(v_{j}^{\prime} U\right)^{r_{i j}^{-}}\right]\right\rangle, \quad i=1,2, \ldots, m .
\end{gathered}
$$

Step 6: Calculate the relative closeness degrees of alternatives

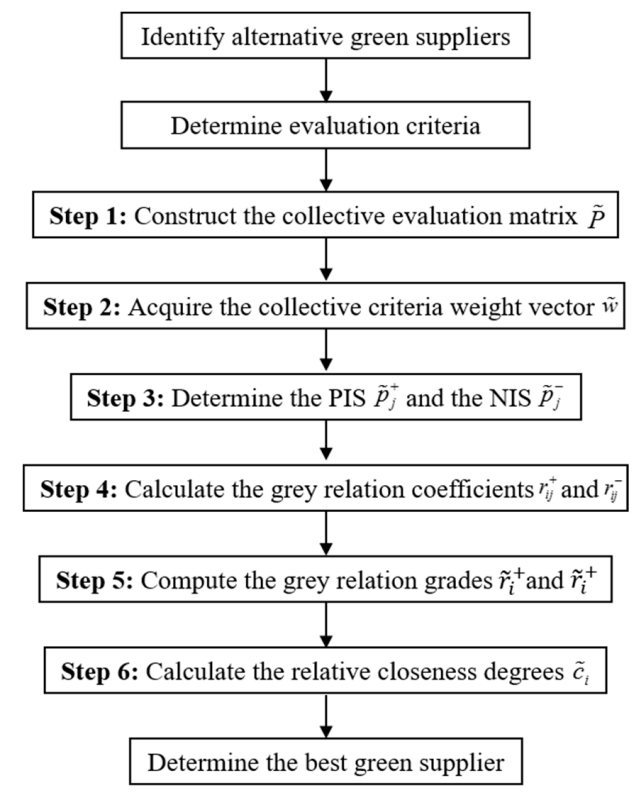

Figure 1. Flowchart of the proposed green supplier selection approach. 
The relative closeness degree $\widetilde{c_{i}}$ of every alternative supplier is calculated by using the following formula:

$$
\widetilde{c}_{i}=\frac{\widetilde{r}_{i}^{+}}{\widetilde{r}_{i}^{+}+\widetilde{r}_{i}^{-}}, \quad i=1,2, \ldots, m
$$

With the purpose of ranking all the alternative green suppliers and selecting the most appropriate one, we need to calculate the expected values $E\left(\widetilde{c}_{i}\right)(i=1,2, \ldots, m)$ and the accuracy degrees $T\left(\widetilde{c}_{i}\right)(1,2, \ldots, m)$, respectively. Finally, we can sort the $m$ alternatives in descending order on the basis of Definition 4 and obtain the optimum green supplier.

\section{Case Illustration}

\subsection{Implementation}

In this section, a case study from Ref. [33] is used for demonstrating the application of the proposed green supplier selection approach. Food processing industry is one of the heavily polluting industries which makes contributes to climate change and global warming. Under great environmental pressure from society, the agri-food sector in a food processing company needs to take actions to control and reduce the environmental impacts of food production $[47,53]$. The case company is one of the leading Iranian manufactures of edible vegetable oils which contributes to the economy of the country; it is International Organization for Standardization (IOS) 14000 certified and undertakes its related environmental responsibilities including improving its suppliers' environmental performance [33]. The main raw materials of the company contain olive oil, palm oil, sunflower oil and soybean oil. The objective of this case study is to assist the company to choose the best green supplier from some alternatives. After initial screening, there are ten alternative suppliers remained for further assessment, including four olive oil suppliers $\left(\mathrm{O}_{1}, \mathrm{O}_{2}, \mathrm{O}_{3}\right.$, and $\left.\mathrm{O}_{4}\right)$, three palm oil suppliers $\left(\mathrm{P}_{1}, \mathrm{P}_{2}\right.$, and $\left.\mathrm{P}_{3}\right)$ and three sunflower-soybean oil suppliers $\left(\mathrm{SS}_{1}, \mathrm{SS}_{2}\right.$, and $\left.\mathrm{SS}_{3}\right)$.

Based on a review of the supplier selection literature, service level, product quality and price are identified as the conventional criteria, and environmental management system is identified as the environmental criterion. These four criteria are represented as $C_{j}(j=1,2,3,4)$ in that order. A committee of five decision makers, $\left(\mathrm{DM}_{k}, k=1,2, \ldots, 5\right)$, is built to give evaluation of suppliers' performance on each criterion and the relative importance of the criteria. In consideration of their different experience and knowledge, the weight vector of the five decision makers is determined as $\lambda=(0.25,0.2,0.3,0.15,0.1)$. The linguistic term sets used to evaluate the suppliers' performance and the criteria importance are given as follows:

$$
\begin{aligned}
& S=\left\{\begin{array}{l}
s_{0}=\text { extremly poor, } s_{1}=\text { very poor, } s_{2}=\text { poor, } s_{3}=\text { medium poor, } s_{4}=\text { fair, } s_{5}=\text { medium good, } \\
\left.s_{6}=\text { good, } s_{7}=\text { very good, } s_{8}=\text { extremely good }\right\},
\end{array}\right. \\
& S_{w}=\left\{\begin{array}{l}
s_{0}^{\prime}=\text { extremly low, } s_{1}^{\prime}=\text { very low, } s_{2}^{\prime}=\text { low, } s_{3}^{\prime}=\text { medium low, } s_{4}^{\prime}=\text { fair, } s_{5}^{\prime}=\text { medium high, } \\
\left.s_{6}^{\prime}=\text { high, } s_{7}^{\prime}=\text { very high, } s_{8}^{\prime}=\text { extremely high }\right\} .
\end{array}\right.
\end{aligned}
$$

The performance assessments of the alternative suppliers with regard to each criterion are in the form of IVIULNs. For example, the assessment results of the ten suppliers offered by the first decision maker $D M_{1}$ are tabulated in Table 1. In addition, the weights of criteria evaluated by the five decision makers are shown in Table 2.

Next, the calculation procedure of the proposed model for the selection of green suppliers is described. We choose the olive oil suppliers as an example and similar steps can be applied to other types of vendors.

Step 1: By Equation (8), the five individual evaluation matrices $\widetilde{P}^{k}(k=1,2, \ldots, 5)$ are aggregated to obtain the collective evaluation matrix $\widetilde{P}=\left[p_{i j}\right]_{10 \times 4}$, as shown in Table 3 . 
Step 2: Opinions of the five decision makers on criteria importance are aggregated based on Equation (9) and the collective weights of the four criteria are derived as follows:

$$
\begin{gathered}
\widetilde{w}_{1}=\left\langle\left[s_{6.513}^{\prime}, s_{7.223}^{\prime}\right],[0.725,0.824],[0.071,0.146]\right\rangle, \widetilde{w}_{2}=\left\langle\left[s_{5.590}^{\prime}, s_{6.789}^{\prime}\right],[0.667,0.818],[0.086,0.158]\right\rangle, \\
\widetilde{w}_{3}=\left\langle\left[s_{4.849}^{\prime}, s_{5.527}^{\prime}\right],[0.648,0.767],[0.100,0.184]\right\rangle, \widetilde{w}_{4}=\left\langle\left[s_{3.936}^{\prime}, s_{4.648}^{\prime}\right],[0.626,0.749],[0.112,0.192]\right\rangle .
\end{gathered}
$$

Step 3: Since service level, product quality and environmental management system are benefit criteria, $J_{1}=\left\{C_{1}, C_{2}, C_{4}\right\}$ and price is a cost criterion, $J_{2}=\left\{C_{3}\right\}$, the PIS and the NIS of the olive oil suppliers are determined as:

$$
\begin{array}{rrr}
\widetilde{P}^{+}=\quad\left(\left\langle\left[s_{5.598}, s_{6.614}\right],[0.673,0.738],[0.071,0.171]\right\rangle,\right. & \left\langle\left[s_{4.512}, s_{5.554}\right],[0.696,0.800],[0.122,0.171]\right\rangle, \\
& \left\langle\left[s_{3.224}, s_{4.084}\right],[0.600,0.714],[0.171,0.246]\right\rangle, & \left.\left\langle\left[s_{6.283}, s_{6.957}\right],[0.706,0.789],[0.071,0.146]\right\rangle\right), \\
\widetilde{P}^{-}=\quad\left(\left\langle\left[s_{1.722}, s_{2.805}\right],[0.553,0.648],[0.171,0.271]\right\rangle,\right. & \left\langle\left[s_{0.000}, s_{2.806}\right],[0.600,0.643],[0.185,0.251]\right\rangle, \\
& \left\langle\left[s_{5.821}, s_{6.430}\right],[0.743,0.823],[0.115,0.176]\right\rangle, & \left.\left\langle\left[s_{4.255}, s_{5.275}\right],[0.653,0.709],[0.131,0.185]\right\rangle\right) .
\end{array}
$$

Step 4: Based on Equations (24) and (25), the grey relation coefficient matrices of the four olive oil suppliers to the PIS and the NIS are computed are shown below:

$$
\begin{aligned}
& R^{+}=\left[r_{i j}^{+}\right]_{4 \times 4}=\left[\begin{array}{llll}
0.404 & 0.738 & 0.995 & 0.608 \\
0.584 & 0.418 & 0.484 & 0.581 \\
0.556 & 1.000 & 0.448 & 0.826 \\
0.378 & 0.349 & 0.750 & 0.484
\end{array}\right], \\
& R^{-}=\left[r_{i j}^{-}\right]_{4 \times 4}=\left[\begin{array}{llll}
0.651 & 0.426 & 0.481 & 0.812 \\
0.467 & 0.671 & 0.812 & 0.855 \\
0.481 & 0.381 & 0.911 & 0.586 \\
0.723 & 0.889 & 0.533 & 1.000
\end{array}\right] .
\end{aligned}
$$

Step 5: The grey relation grades of each supplier to the PIS and the NIS are calculated by using Equations (28) and (29), and the results are listed as follows:

$$
\begin{aligned}
& \widetilde{r}_{1}^{+}=\left\langle\left[s_{14.235}^{\prime}, s_{16.225}^{\prime}\right],[0.948,0.986],[0.002,0.008]\right\rangle, \widetilde{r}_{2}^{+}=\left\langle\left[s_{10.907}^{\prime}, s_{12.415}^{\prime}\right],[0.898,0.960],[0.007,0.026]\right\rangle, \\
& \widetilde{r}_{3}^{+}=\left\langle\left[s_{14.995}^{\prime}, s_{17.129}^{\prime}\right],[0.955,0.988],[0.001,0.006]\right\rangle, \widetilde{r}_{4}^{+}=\left\langle\left[s_{10.047}^{\prime}, s_{11.490}^{\prime}\right],[0.881,0.951],[0.010,0.032]\right\rangle ; \\
& \widetilde{r}_{1}^{-}=\left\langle\left[s_{12.303}^{\prime}, s_{14.031}^{\prime}\right],[0.926,0.957],[0.004,0.015]\right\rangle, \widetilde{r}_{2}^{-}=\left\langle\left[s_{14.337}^{\prime}, s_{16.397}^{\prime}\right],[0.952,0.987],[0.001,0.007]\right\rangle, \\
& \widetilde{r}_{3}^{-}=\left\langle\left[s_{12.124}^{\prime}, s_{13.823}^{\prime}\right],[0.923,0.973],[0.004,0.016]\right\rangle, \widetilde{r}_{4}^{-}=\left\langle\left[s_{16.591}^{\prime}, s_{18.860}^{\prime}\right],[0.968,0.993],[0.001,0.004]\right\rangle .
\end{aligned}
$$

Step 6: By utilizing Equation (33), the relative closeness degrees $\widetilde{c}_{i}(i=1,2,3,4)$ of the four olive oil suppliers are calculated as shown below:

$$
\begin{aligned}
& \widetilde{c}_{1}=\left\langle\left[s_{0.536}^{\prime}, s_{0.537}^{\prime}\right],[0.948,0.986],[0.002,0.008]\right\rangle, \widetilde{c}_{2}=\left\langle\left[s_{0.431}^{\prime}, s_{0.431}^{\prime}\right],[0.898,0.960],[0.007,0.008]\right\rangle, \\
& \widetilde{c}_{3}=\left\langle\left[s_{0.552}^{\prime}, s_{0.553}^{\prime}\right],[0.955,0.988],[0.001,0.006]\right\rangle, \widetilde{c}_{4}=\left\langle\left[s_{0.378}^{\prime}, s_{0.393}^{\prime}\right],[0.881,0.951],[0.010,0.032]\right\rangle .
\end{aligned}
$$

By computing the expect values and the accuracy degrees of the relative closeness degrees $\widetilde{c}_{i}(i=1,2,3,4)$, the ranking of the four olive oil suppliers is obtained as $\mathrm{O}_{3} \succ \mathrm{O}_{1} \succ \mathrm{O}_{2} \succ \mathrm{O}_{4}$. Therefore, $\mathrm{O}_{3}$ is the most appropriate green supplier among the alternative olive oil suppliers.

The palm oil suppliers and sunflower-soybean oil suppliers can be evaluated and ranked in the same way. The ranking orders obtained are $\mathrm{P}_{1} \succ \mathrm{P}_{2} \succ \mathrm{P}_{3}$ and $\mathrm{SS}_{1} \succ \mathrm{SS}_{2} \succ \mathrm{SS}_{3}$, respectively. Thus, the company can select $P_{1}$ and $S_{1}$ as the palm oil supplier and the sunflower-soybean oil supplier to them for procurement. 
Table 1. Performance assessments of the alternatives by the first decision maker.

\begin{tabular}{|c|c|c|c|c|c|}
\hline \multirow{2}{*}{ Kind of Suppliers } & \multirow{2}{*}{ Suppliers } & \multicolumn{4}{|c|}{ Criteria } \\
\hline & & $\mathrm{C}_{1}$ & $\mathrm{C}_{2}$ & $\mathrm{C}_{3}$ & $\mathrm{C}_{4}$ \\
\hline Olive oil & $\begin{array}{l}\mathrm{O}_{1} \\
\mathrm{O}_{2} \\
\mathrm{O}_{3} \\
\mathrm{O}_{4}\end{array}$ & $\begin{array}{l}\left\langle\left[s_{4}, s_{5}\right],[0.7,0.8],[0.1,0.2]\right\rangle \\
\left\langle\left[s_{6}, s_{7}\right],[0.6,0.7],[0.2,0.3]\right\rangle \\
\left\langle\left[s_{3}, s_{4}\right],[0.7,0.7],[0.1,0.2]\right\rangle \\
\left\langle\left[s_{1}, s_{2}\right],[0.6,0.7],[0.1,0.2]\right\rangle\end{array}$ & $\begin{array}{l}\left\langle\left[s_{3}, s_{4}\right],[0.6,0.7],[0.1,0.2]\right\rangle \\
\left\langle\left[s_{4}, s_{5}\right],[0.6,0.6],[0.2,0.2]\right\rangle \\
\left\langle\left[s_{7}, s_{8}\right],[0.7,0.8],[0.1,0.2]\right\rangle \\
\left\langle\left[s_{0}, s_{1}\right],[0.7,0.7],[0.1,0.2]\right\rangle\end{array}$ & $\begin{array}{l}\left\langle\left[s_{3}, s_{3}\right],[0.6,0.7],[0.2,0.3]\right\rangle \\
\left\langle\left[s_{4}, s_{4}\right],[0.8,0.9],[0.1,0.1]\right\rangle \\
\left\langle\left[s_{5}, s_{6}\right],[0.6,0.7],[0.1,0.2]\right\rangle \\
\left\langle\left[s_{2}, s_{2}\right],[0.8,0.8],[0.1,0.2]\right\rangle\end{array}$ & $\begin{array}{c}\left\langle\left[s_{6}, s_{7}\right],[0.7,0.8],[0.1,0.1]\right\rangle \\
\left\langle\left[s_{5}, s_{6}\right],[0.7,0.7],[0.1,0.2]\right\rangle \\
\left\langle\left[s_{6}, s_{7}\right],[0.7,0.7],[0.1,0.2]\right\rangle \\
\left\langle\left[s_{3}, s_{4}\right],[0.6,0.7],[0.1,0.1]\right\rangle\end{array}$ \\
\hline Palm oil & $\begin{array}{l}\mathrm{P}_{1} \\
\mathrm{P}_{2} \\
\mathrm{P}_{3}\end{array}$ & $\begin{array}{l}\left\langle\left[s_{6}, s_{7}\right],[0.6,0.6],[0.2,0.3]\right\rangle \\
\left\langle\left[s_{2}, s_{3}\right],[0.6,0.7],[0.2,0.2]\right\rangle \\
\left\langle\left[s_{5}, s_{6}\right],[0.7,0.8],[0.1,0.1]\right\rangle\end{array}$ & $\begin{array}{l}\left\langle\left[s_{5}, s_{6}\right],[0.7,0.8],[0.1,0.2]\right\rangle \\
\left\langle\left[s_{3}, s_{3}\right],[0.7,0.7],[0.1,0.2]\right\rangle \\
\left\langle\left[s_{4}, s_{4}\right],[0.7,0.8],[0.1,0.1]\right\rangle\end{array}$ & $\begin{array}{l}\left\langle\left[s_{5}, s_{5}\right],[0.7,0.8],[0.1,0.1]\right\rangle \\
\left\langle\left[s_{3}, s_{4}\right],[0.6,0.7],[0.1,0.2]\right\rangle \\
\left\langle\left[s_{4}, s_{5}\right],[0.7,0.8],[0.1,0.2]\right\rangle\end{array}$ & $\begin{array}{l}\left\langle\left[s_{5}, s_{6}\right],[0.7,0.8],[0.1,0.1]\right\rangle \\
\left\langle\left[s_{1}, s_{2}\right],[0.7,0.7],[0.1,0.2]\right\rangle \\
\left\langle\left[s_{4}, s_{5}\right],[0.6,0.7],[0.1,0.3]\right\rangle\end{array}$ \\
\hline Sunflower-soybean oil & $\begin{array}{l}\mathrm{SS}_{1} \\
\mathrm{SS}_{2} \\
\mathrm{SS}_{3}\end{array}$ & $\begin{array}{l}\left\langle\left[s_{7}, s_{8}\right],[0.7,0.8],[0.1,0.2]\right\rangle \\
\left\langle\left[s_{5}, s_{6}\right],[0.6,0.7],[0.1,0.2]\right\rangle \\
\left\langle\left[s_{2}, s_{3}\right],[0.6,0.7],[0.2,0.2]\right\rangle\end{array}$ & $\begin{array}{l}\left\langle\left[s_{4}, s_{5}\right],[0.6,0.7],[0.1,0.2]\right\rangle \\
\left\langle\left[s_{5}, s_{5}\right],[0.6,0.7],[0.2,0.2]\right\rangle \\
\left\langle\left[s_{7}, s_{8}\right],[0.6,0.7],[0.1,0.2]\right\rangle\end{array}$ & $\begin{array}{l}\left\langle\left[s_{7}, s_{7}\right],[0.7,0.7],[0.1,0.2]\right\rangle \\
\left\langle\left[s_{4}, s_{5}\right],[0.7,0.8],[0.1,0.2]\right\rangle \\
\left\langle\left[s_{4}, s_{5}\right],[0.7,0.7],[0.1,0.2]\right\rangle\end{array}$ & $\begin{array}{l}\left\langle\left[s_{4}, s_{4}\right],[0.7,0.7],[0.1,0.2]\right\rangle \\
\left\langle\left[s_{5}, s_{6}\right],[0.6,0.7],[0.1,0.2]\right\rangle \\
\left\langle\left[s_{4}, s_{5}\right],[0.7,0.8],[0.1,0.1]\right\rangle\end{array}$ \\
\hline
\end{tabular}

Table 2. Criteria weight ratings by the five decision makers.

\begin{tabular}{|c|c|c|c|c|}
\hline \multirow{2}{*}{ Decision Makers } & \multicolumn{4}{|c|}{ Criteria } \\
\hline & $\mathrm{C}_{1}$ & $\mathrm{C}_{2}$ & $\mathrm{C}_{3}$ & $\mathrm{C}_{4}$ \\
\hline $\mathrm{DM}_{1}$ & $\left\langle\left[s_{6}^{\prime}, s_{7}^{\prime}\right],[0.8,0.9],[0.1,0.1]\right\rangle$ & $\left\langle\left[s_{6}^{\prime}, s_{7}^{\prime}\right],[0.7,0.8],[0.1,0.1]\right\rangle$ & $\left\langle\left[s_{5}^{\prime}, s_{6}^{\prime}\right],[0.6,0.7],[0.1,0.3]\right\rangle$ & $\left.\left.s_{4}^{\prime}\right],[0.7,0.8],[0.2,0.2]\right\rangle$ \\
\hline $\mathrm{DM}_{2}$ & $\left\langle\left[s_{7}^{\prime}, s_{8}^{\prime}\right],[0.7,0.8],[0.1,0.2]\right\rangle$ & $6],[0.7,0.8],[0.1,0.2]\rangle$ & $\left.\left.s_{6}^{\prime}\right],[0.7,0.7],[0.1,0.2]\right\rangle$ & $\left.\left.s_{4}^{\prime}\right],[0.7,0.9],[0.1,0.1]\right\rangle$ \\
\hline $\mathrm{DM}_{3}$ & $\left\langle\left[s_{7}^{\prime}, s_{7}^{\prime}\right],[0.8,0.8],[0.0,0.1]\right\rangle$ & $\left\langle\left[s_{7}^{\prime}, s_{8}^{\prime}\right],[0.7,0.9],[0.1,0.1]\right\rangle$ & $\left.\left[s_{4}^{\prime}, s_{5}^{\prime}\right],[0.7,0.8],[0.1,0.1]\right\rangle$ & $\left.\left.s_{5}^{\prime}\right],[0.6,0.7],[0.1,0.2]\right\rangle$ \\
\hline $\mathrm{DM}_{4}$ & $\left.\left\langle s_{7}^{\prime}, s_{8}^{\prime}\right],[0.6,0.8],[0.1,0.2]\right\rangle$ & $\left\langle\left[s_{7}^{\prime}, s_{8}^{\prime}\right],[0.7,0.8],[0.0,0.2]\right\rangle$ & $\left\langle\left[s_{5}^{\prime}, s_{5}^{\prime}\right],[0.6,0.9],[0.1,0.1]\right\rangle$ & $\left\langle\left[s_{5}^{\prime}, s_{6}^{\prime}\right],[0.5,0.7],[0.0,0.2]\right\rangle$ \\
\hline $\mathrm{DM}_{5}$ & $\left\langle\left[s_{5}^{\prime}, s_{6}^{\prime}\right],[0.6,0.8],[0.1,0.2]\right\rangle$ & $\left\langle\left[s_{5}^{\prime}, s_{6}^{\prime}\right],[0.5,0.7],[0.1,0.3]\right\rangle$ & $\left\langle\left[s_{5}^{\prime}, s_{6}^{\prime}\right],[0.6,0.8],[0.1,0.2]\right\rangle$ & $\left\langle\left[s_{5}^{\prime}, s_{5}^{\prime}\right],[0.6,0.6],[0.1,0.3]\right\rangle$ \\
\hline
\end{tabular}


Table 3. The collective evaluation matrix.

\begin{tabular}{|c|c|c|c|c|c|}
\hline \multirow{2}{*}{$\begin{array}{l}\text { Kind of } \\
\text { Suppliers }\end{array}$} & \multirow{2}{*}{ Suppliers } & \multicolumn{4}{|c|}{ Criteria } \\
\hline & & $\mathrm{C}_{1}$ & $\mathrm{C}_{2}$ & $\mathrm{C}_{3}$ & $\mathrm{C}_{4}$ \\
\hline Olive oil & $\begin{array}{l}\mathrm{O}_{1} \\
\mathrm{O}_{2} \\
\mathrm{O}_{3} \\
\mathrm{O}_{4} \\
\end{array}$ & $\begin{array}{l}\left\langle\left[s_{1.866}, s_{2.958}\right],[0.673,0.738],[0.071,0.171]\right\rangle \\
\left\langle\left[s_{5.598}, s_{6.614}\right],[0.553,0.648],[0.171,0.271]\right\rangle \\
\left\langle\left[s_{3.458}, s_{4.839}\right],[0.676,0.718],[0.071,0.171]\right\rangle \\
\left\langle\left[s_{1.722}, s_{2.805}\right],[0.640,0.711],[0.071,0.187]\right\rangle\end{array}$ & $\begin{array}{l}\left\langle\left[s_{3.866}, s_{4.891}\right],[0.696,0.753],[0.122,0.190]\right\rangle \\
\left\langle\left[s_{2.681}, s_{3.852}\right],[0.600,0.643],[0.185,0.251]\right\rangle \\
\left\langle\left[s_{4.512}, s_{5.554}\right],[0.676,0.800],[0.126,0.171]\right\rangle \\
\left\langle\left[s_{0.000}, s_{2.806}\right],[0.610,0.687],[0.148,0.176]\right\rangle\end{array}$ & $\begin{array}{l}\left\langle\left[s_{3.224}, s_{4.084}\right],[0.678,0.751],[0.171,0.246]\right\rangle \\
\left\langle\left[s_{4.830}, s_{5.275}\right],[0.743,0.823],[0.115,0.176]\right\rangle \\
\left\langle\left[s_{5.821}, s_{6.430}\right],[0.724,0.762],[0.126,0.236]\right\rangle \\
\left\langle\left[s_{3.512}, s_{4.143}\right],[0.659,0.743],[0.126,0.185]\right\rangle\end{array}$ & $\begin{array}{l}\left\langle\left[s_{4.704}, s_{5.720}\right],[0.673,0.789],[0.100,0.146]\right\rangle \\
\left\langle\left[s_{4.884}, s_{5.638}\right],[0.655,0.718],[0.071,0.146]\right\rangle \\
\left\langle\left[s_{6.283}, s_{6.957}\right],[0.706,0.753],[0.131,0.185]\right\rangle \\
\left\langle\left[s_{4.255}, s_{5.275}\right],[0.653,0.709],[0.090,0.179]\right\rangle\end{array}$ \\
\hline Palm oil & $\begin{array}{l}\mathrm{P}_{1} \\
\mathrm{P}_{2} \\
\mathrm{P}_{3}\end{array}$ & $\begin{array}{l}\left\langle\left[s_{6.382}, s_{7.384}\right],[0.629,0.711],[0.146,0.196]\right\rangle \\
\left\langle\left[s_{2.822}, s_{3.657}\right],[0.653,0.743],[0.105,0.148]\right\rangle \\
\left\langle\left[s_{4.394}, s_{5.405}\right],[0.707,0.800],[0.071,0.126]\right\rangle\end{array}$ & $\begin{array}{l}\left\langle\left[s_{5.632}, s_{6.382}\right],[0.700,0.738],[0.110,0.231]\right\rangle \\
\left\langle\left[s_{2.470}, s_{3.318}\right],[0.643,0.700],[0.156,0.246]\right\rangle \\
\left\langle\left[s_{3.886}, s_{4.276}\right],[0.684,0.762],[0.090,0.192]\right\rangle\end{array}$ & $\begin{array}{c}\left\langle\left[s_{5}, s_{5.378}\right],[0.700,0.800],[0.075,0.131]\right\rangle \\
\left\langle\left[s_{2.499}, s_{3.112}\right],[0.648,0.709],[0.100,0.171]\right\rangle \\
\left\langle\left[s_{4.657}, s_{5.578}\right],[0.718,0.784],[0.056,0.146]\right\rangle\end{array}$ & $\begin{array}{c}\left\langle\left[s_{5.378}, s_{6.058}\right],[0.678,0.809],[0.046,0.120]\right\rangle \\
\left\langle\left[s_{1.899}, s_{2.564}\right],[0.668,0.780],[0.085,0.146]\right\rangle \\
\left\langle\left[s_{3.565}, s_{4.573}\right],[0.609,0.709],[0.046,0.198]\right\rangle\end{array}$ \\
\hline $\begin{array}{l}\text { Sunflower-soybean } \\
\quad \text { oil }\end{array}$ & $\begin{array}{l}\mathrm{SS}_{1} \\
\mathrm{SS}_{2} \\
\mathrm{SS}_{3}\end{array}$ & $\begin{array}{l}\left\langle\left[s_{6.123}, s_{6.804}\right],[0.723,0.792],[0.056,0.126]\right\rangle \\
\left\langle\left[s_{4.148}, s_{5.169}\right],[0.578,0.701],[0.081,0.176]\right\rangle \\
\left\langle\left[s_{3.047}, s_{3.901}\right],[0.590,0.753],[0.136,0.200]\right\rangle\end{array}$ & $\begin{array}{l}\left\langle\left[s_{3.867}, s_{4.884}\right],[0.643,0.773],[0.120,0.200]\right\rangle \\
\left\langle\left[s_{33.337}, s_{4.194}\right],[0.547,0.687],[0.126,0.200]\right\rangle \\
\left\langle\left[s_{3.152}, s_{4.239}\right],[0.587,0.687],[0.068,0.171]\right\rangle\end{array}$ & $\begin{array}{l}\left\langle\left[s_{5.669}, s_{6.118}\right],[0.678,0.698],[0.056,0.146]\right\rangle \\
\left\langle\left[s_{2.297}, s_{2.692}\right],[0.612,0.680],[0.166,0.251]\right\rangle \\
\left\langle\left[s_{3.365}, s_{4.128}\right],[0.683,0.783],[0.111,0.156]\right\rangle\end{array}$ & $\begin{array}{l}\left\langle\left[s_{4.128}, s_{4.522}\right],[0.629,0.753],[0.076,0.156]\right\rangle \\
\left\langle\left[s_{2.32}, s_{2.849}\right],[0.568,0.700],[0.056,0.148]\right\rangle \\
\left\langle\left[s_{4.276}, s_{4.884}\right],[0.706,0.828],[0.081,0.126]\right\rangle\end{array}$ \\
\hline
\end{tabular}




\subsection{Comparisons and Discussion}

To further validate the proposed approach, we make a comparison to analyze some existing green supplier selection methods by using the above example, which include the fuzzy TOPSIS, the fuzzy VIKOR and the fuzzy GRA methods [33]. The ranking results of the ten suppliers by utilizing the three approaches are displayed in Table 4.

Table 4. Ranking comparison.

\begin{tabular}{cccccc}
\hline Kind of Suppliers & Suppliers & Fuzzy TOPSIS & Fuzzy VIKOR & Fuzzy GRA & $\begin{array}{c}\text { The proposed } \\
\text { Approach }\end{array}$ \\
\hline \multirow{5}{*}{ Olive oil } & $\mathrm{O}_{1}$ & 3 & 3 & 3 & 2 \\
& $\mathrm{O}_{2}$ & 2 & 2 & 2 & 3 \\
& $\mathrm{O}_{3}$ & 1 & 1 & 1 & 1 \\
& $\mathrm{O}_{4}$ & 4 & 4 & 4 & 4 \\
\hline \multirow{3}{*}{ Palm oil } & $\mathrm{P}_{1}$ & 1 & 1 & 3 & 2 \\
& $\mathrm{P}_{2}$ & 3 & 3 & 2 & 3 \\
\hline \multirow{3}{*}{ Sunflower-soybean oil } & $\mathrm{P}_{3}$ & 2 & 2 & 3 & 1 \\
& $\mathrm{SS}_{1}$ & 1 & 3 & 2 & 2 \\
\hline
\end{tabular}

From Table 4, it can be seen that the optimal suppliers obtained by the proposed approach and the three comparative methods are the same: $\mathrm{O}_{3}, \mathrm{P}_{1}$ and $\mathrm{SS}_{1}$ are respectively the most suitable green suppliers of olive oil, palm oil and sunflower-soybean oil. This reveals the effectiveness of the green supplier selection model proposed in this study. In addition, there are still some differences between the ranking results acquired by the proposed approach and the three comparative methods. The least optimal green suppliers are $\mathrm{O}_{4}, \mathrm{P}_{3}$ and $\mathrm{SS}_{3}$ of olive oil, palm oil and sunflower-soybean oil by the proposed approach. According to the three comparative methods, the least optimal green suppliers are $\mathrm{O}_{4}, \mathrm{P}_{2}$ and $\mathrm{SS}_{2}$, correspondingly. The reasons that bring the inconsistence mainly lie in the characteristics of the three comparative methods. First, triangular fuzzy numbers are applied in the three comparative methods. In contrast, the IVIULSs used in the proposed approach can better reflect the uncertainty and vagueness of decision makers' assessments. Second, GRA, TOPSIS, VIKOR are utilized to rank alternatives in the three comparative methods, respectively. But the GRA-TOPSIS can reflect the similarity between case data curves and the relationships of these curves simultaneously as compared with the GRA and TOPSIS; the GRA-TOPSIS is more convenient and rapid in determining the best supplier by comparing with the VIKOR. Therefore, the ranking result of the alternative suppliers produced by the proposed approach is more accurate and reasonable.

In comparison with the existing approaches for the selection of green suppliers, the proposed green supplier selection model has the following strength points:

- The approach can well reflect the uncertainty and fuzziness of decision makers' subjective data by utilizing IVIULSs. This enables decision makers to express their judgments more realistically and makes the assessment easier to be carried out.

- Both quantitative and qualitative criteria can be considered in the green supplier selection which makes the developed model more reasonable. The proposed approach is a general method and not limited to the four criteria listed in the case study, but applicable to any number of criteria.

- By utilizing the GRA-TOPSIS method, a more precise and reasonable ranking of alternative suppliers can be obtained based on the basic principles of GRA and TOPSIS methods, which facilitates the company to choose the most appropriate green supplier. 


\section{Conclusions}

In this study, we presented a novel integrated approach by integrating IVIULSs and the GRA-TOPSIS method to assess and select the best green supplier under uncertain information context. In the proposed approach, IVIULSs have been used to represent decision makers' diversity evaluations of alternatives; the GRA-TOPSIS method has been utilized to derive the optimum supplier with respect to economic criteria and environmental criteria. Finally, we made use of an empirical example of the agri-food industry to illustrate the effectiveness and practicability of the proposed green supplier selection model. This work has important implications for procurement and supply management professionals. By using IVIULSs, managers can more effectively handle decision makers' diversity assessments on the green performance of alternatives. The released model also aid managers to obtain a more reasonable and credible ranking of all the evaluation suppliers by combining GRA and TOPSIS methods. It is expected that the integrated formulation will provide a useful and flexible tool for managers to select the most preferred green supplier in practices, which will enable organizations to become more competitive while achieving sustainable development. Besides, the green supplier selection procedure introduced in this paper can be used to help a company's management involved in the purchasing activities to construct a consensus ranking of green suppliers while taking into account viewpoints of different stakeholders within the company.

Despite its contributions, this study has several weakness point, which may be addressed by future research. Firstly, we assume that the evaluation criteria are independent in the proposed approach. In many actual cases, the criteria may have interdependent and feedback relationships because of the complexity of evaluation systems. Thus, in the future, a modified approach is suggested to be developed which can reflect the network relationship and deal with the interdependence of evaluation criteria. Secondly, the weights of criteria are determined based on decision makers' subjective judgements, which may result in biased ranking of alternative green suppliers. Therefore, it is recommended to optimize the proposed green supplier selection model by considering objective weights of evaluation criteria in future work. Thirdly, the proposed approach can not consider decision makers' psychological behaviors in the ranking of green suppliers. In future research, it is recommended to consider the attitudinal character of decision makers in the green supplier selection process as different risk attitudes (e.g., optimistic and pessimistic) may have different effects on the results. In addition, the integrated framework proposed in this paper is a general technique, which can easily be adjusted to solve other green supplier selection problems involving any number of alternatives and any number of criteria.

Acknowledgments: The authors are very grateful to the editor and reviewers for their insightful and constructive comments and suggestions which are very helpful in improving the quality of the paper. This work was partially supported by the National Natural Science Foundation of China (Nos. 61773250, 71402090 and 71701153) and the Shanghai Youth Top-Notch Talent Development Program.

Author Contributions: The individual contribution and responsibilities of the authors were as follows: Hua Shi and $\mathrm{Hu}$-Chen Liu together designed research, Mei-Yun Quan and Chun-Yan Duan provided extensive advices throughout the study regarding to abstract, introduction, research design, research methodology, findings and revise the manuscript. The discussion was a team task. All authors have read and approved the final manuscript.

Conflicts of Interest: The authors declare no conflict of interest.

\section{References}

1. Masi, D.; Day, S.; Godsell, J. Supply chain configurations in the circular economy: A systematic literature review. Sustainability 2017, 9, 1602. [CrossRef]

2. Centobelli, P.; Cerchione, R.; Esposito, E. Environmental sustainability and energy-efficient supply chain management: A review of research trends and proposed guidelines. Energies 2018, 11, 275. [CrossRef]

3. Liu, W.; Bai, E.; Liu, L.; Wei, W. A framework of sustainable service supply chain management: A literature review and research agenda. Sustainability 2017, 9, 421. [CrossRef] 
4. Fallahpour, A.; Udoncy Olugu, E.; Nurmaya Musa, S.; Yew Wong, K.; Noori, S. A decision support model for sustainable supplier selection in sustainable supply chain management. Comput. Ind. Eng. 2017, 105, 391-410. [CrossRef]

5. Pourhejazy, P.; Kwon, O. The new generation of operations research methods in supply chain optimization: A review. Sustainability 2016, 8, 1033. [CrossRef]

6. Luthra, S.; Govindan, K.; Kannan, D.; Mangla, S.K.; Garg, C.P. An integrated framework for sustainable supplier selection and evaluation in supply chains. J. Clean. Prod. 2017, 140 Pt 3, 1686-1698. [CrossRef]

7. Qin, J.; Liu, X.; Pedrycz, W. An extended TODIM multi-criteria group decision making method for green supplier selection in interval type-2 fuzzy environment. Eur. J. Oper. Res. 2017, 258, 626-638. [CrossRef]

8. Hamdan, S.; Cheaitou, A. Supplier selection and order allocation with green criteria: An MCDM and multi-objective optimization approach. Comput. Oper. Res. 2017, 81, 282-304. [CrossRef]

9. Centobelli, P.; Cerchione, R.; Esposito, E. Developing the WH2 framework for environmental sustainability in logistics service providers: A taxonomy of green initiatives. J. Clean. Prod. 2017, 165, 1063-1077. [CrossRef]

10. Zhao, J.; You, X.-Y.; Liu, H.-C.; Wu, S.-M. An extended VIKOR method using intuitionistic fuzzy sets and combination weights for supplier selection. Symmetry 2017, 9, 169. [CrossRef]

11. Wang, K.-Q.; Liu, H.-C.; Liu, L.; Huang, J. Green supplier evaluation and selection using cloud model theory and the QUALIFLEX method. Sustainability 2017, 9, 688. [CrossRef]

12. Yazdani, M.; Chatterjee, P.; Zavadskas, E.K.; Hashemkhani Zolfani, S. Integrated QFD-MCDM framework for green supplier selection. J. Clean. Prod. 2017, 142, 3728-3740. [CrossRef]

13. Uygun, Ö.; Dede, A. Performance evaluation of green supply chain management using integrated fuzzy multi-criteria decision making techniques. Comput. Ind. Eng. 2016, 102, 502-511. [CrossRef]

14. Keshavarz Ghorabaee, M.; Zavadskas, E.K.; Amiri, M.; Esmaeili, A. Multi-criteria evaluation of green suppliers using an extended WASPAS method with interval type-2 fuzzy sets. J. Clean. Prod. 2016, 137, 213-229. [CrossRef]

15. Rodríguez, R.M.; Labella, Á.; Martínez, L. An overview on fuzzy modelling of complex linguistic preferences in decision making. Int. J. Comput. Intell. Syst. 2016, 9 (Suppl. 1), 81-94. [CrossRef]

16. Rodríguez, R.M.; Martínez, L. An analysis of symbolic linguistic computing models in decision making. Int. J. Gen. Syst. 2013, 42, 121-136. [CrossRef]

17. $\mathrm{Xu}, \mathrm{Z}$. Induced uncertain linguistic OWA operators applied to group decision making. Inf. Fusion 2006, 7, 231-238. [CrossRef]

18. $\mathrm{Xu}, \mathrm{Z}$.S. Uncertain linguistic aggregation operators based approach to multiple attribute group decision making under uncertain linguistic environment. Inf. Sci. 2004, 168, 171-184. [CrossRef]

19. Li, D.F. TOPSIS-based nonlinear-programming methodology for multiattribute decision making with interval-valued intuitionistic fuzzy sets. IEEE Trans. Fuzzy Syst. 2010, 18, 299-311. [CrossRef]

20. Meng, F.; Tan, C.; Zhang, Q. The induced generalized interval-valued intuitionistic fuzzy hybrid Shapley averaging operator and its application in decision making. Knowl. Based Syst. 2013, 42, 9-19. [CrossRef]

21. Liu, P. Some geometric aggregation operators based on interval intuitionistic uncertain linguistic variables and their application to group decision making. Appl. Math. Model. 2013, 37, 2430-2444. [CrossRef]

22. Wan, J. Model for evaluating the design patterns of the Micro-Air vehicle under interval-valued intuitionistic uncertain linguistic environment. J. Intell. Fuzzy Syst. 2016, 30, 2963-2969. [CrossRef]

23. Liu, T.; Wang, C.; Li, X. Model for evaluating the management performance of the sport grounds with interval-valued intuitionistic uncertain linguistic information. J. Intell. Fuzzy Syst. 2016, 31, 1535-1544. [CrossRef]

24. Kan, S.; Guo, F.; Li, S. An approach to evaluating the knowledge management performance with interval-valued intuitionistic uncertain linguistic information. J. Intell. Fuzzy Syst. 2016, 30, 1557-1565. [CrossRef]

25. Meng, F.; Chen, X.; Zhang, Q. Some interval-valued intuitionistic uncertain linguistic Choquet operators and their application to multi-attribute group decision making. Appl. Math. Model. 2014, 38, 2543-2557. [CrossRef]

26. Meng, F.; Chen, X. Correlation coefficient of interval-valued intuitionistic uncertain linguistic sets and its application. Cybern. Syst. 2017, 48, 114-135. [CrossRef]

27. Meng, F.; Chen, X.; Zhang, Q. An approach to interval-valued intuitionistic uncertain linguistic multi-attribute group decision making. Int. J. Mach. Learn. Cybern. 2015, 6, 859-871. [CrossRef] 
28. Büyüközkan, G.; Göçer, F. Application of a new combined intuitionistic fuzzy MCDM approach based on axiomatic design methodology for the supplier selection problem. Appl. Soft Comput. 2017, 52, 1222-1238. [CrossRef]

29. Lima Junior, F.R.; Carpinetti, L.C.R. A multicriteria approach based on Fuzzy QFD for choosing criteria for supplier selection. Comput. Ind. Eng. 2016, 101, 269-285. [CrossRef]

30. Deng, J.L. Introduction to gray system theory. J. Grey Syst. 1989, 1, 1-24.

31. Liu, H.-C.; Wang, L.-E.; You, X.-Y.; Wu, S.-M. Failure mode and effect analysis with extended grey relational analysis method in cloud setting. Total Qual. Manag. Bus. Excell. 2017. [CrossRef]

32. Tseng, M.L.; Lim, M.; Wu, K.J.; Zhou, L.; Bui, D.T.D. A novel approach for enhancing green supply chain management using converged interval-valued triangular fuzzy numbers-grey relation analysis. Resour. Conserv. Recycl. 2018, 128, 122-133. [CrossRef]

33. Banaeian, N.; Mobli, H.; Fahimnia, B.; Nielsen, I.E.; Omid, M. Green supplier selection using fuzzy group decision making methods: A case study from the agri-food industry. Comput. Oper. Res. 2018, 89, 337-347. [CrossRef]

34. Hwang, C.L.; Yoon, K. Multiple Attributes Decision Making Methods and Applications; Springer: Berlin, Germany, 1981.

35. Lu, C.; You, J.X.; Liu, H.C.; Li, P. Health-care waste treatment technology selection using the interval 2-tuple induced TOPSIS method. Int. J. Environ. Res. Public Health 2016, 13, 562. [CrossRef] [PubMed]

36. Ameri, A.A.; Pourghasemi, H.R.; Cerda, A. Erodibility prioritization of sub-watersheds using morphometric parameters analysis and its mapping: A comparison among TOPSIS, VIKOR, SAW, and CF multi-criteria decision making models. Sci. Total Environ. 2018, 613-614, 1385-1400. [CrossRef]

37. Wang, C.-Y.; Chen, S.-M. Multiple attribute decision making based on interval-valued intuitionistic fuzzy sets, linear programming methodology, and the extended TOPSIS method. Inf. Sci. 2017, 397-398, 155-167. [CrossRef]

38. Wu, W.; Peng, Y. Extension of grey relational analysis for facilitating group consensus to oil spill emergency management. Ann. Oper. Res. 2016, 238, 615-635. [CrossRef]

39. Kirubakaran, B.; Ilangkumaran, M. Selection of optimum maintenance strategy based on FAHP integrated with GRA-TOPSIS. Ann. Oper. Res. 2016, 245, 285-313. [CrossRef]

40. Ran, R.; Wang, B.J. Combining grey relational analysis and TOPSIS concepts for evaluating the technical innovation capability of high technology enterprises with fuzzy information. J. Intell. Fuzzy Syst. 2015, 29, 1301-1309. [CrossRef]

41. Sakthivel, G.; Ilangkumaran, M.; Nagarajan, G.; Priyadharshini, G.V.; Dinesh Kumar, S.; Satish Kumar, S.; Suresh, K.S.; Thirumalai Selvan, G.; Thilakavel, T. Multi-criteria decision modelling approach for biodiesel blend selection based on GRA-TOPSIS analysis. Int. J. Ambient Energy 2014, 35, 139-154. [CrossRef]

42. Awasthi, A.; Govindan, K.; Gold, S. Multi-tier sustainable global supplier selection using a fuzzy AHP-VIKOR based approach. Int. J. Prod. Econ. 2018, 195, 106-117. [CrossRef]

43. Yu, Q.; Hou, F. An approach for green supplier selection in the automobile manufacturing industry. Kybernetes 2016, 45, 571-588. [CrossRef]

44. Yazdani, M.; Hashemkhani Zolfani, S.; Zavadskas, E.K. New integration of MCDM methods and QFD in the selection of green suppliers. J. Bus. Econ. Manag. 2016, 17, 1097-1113. [CrossRef]

45. Liou, J.J.H.; Tamošaitienè, J.; Zavadskas, E.K.; Tzeng, G.-H. New hybrid COPRAS-G MADM Model for improving and selecting suppliers in green supply chain management. Int. J. Prod. Res. 2016, 54, 114-134. [CrossRef]

46. Govindan, K.; Rajendran, S.; Sarkis, J.; Murugesan, P. Multi criteria decision making approaches for green supplier evaluation and selection: A literature review. J. Clean. Prod. 2015, 98, 66-83. [CrossRef]

47. Govindan, K.; Kadziński, M.; Sivakumar, R. Application of a novel PROMETHEE-based method for construction of a group compromise ranking to prioritization of green suppliers in food supply chain. Omega 2017, 71, 129-145. [CrossRef]

48. Tavana, M.; Yazdani, M.; Di Caprio, D. An application of an integrated ANP-QFD framework for sustainable supplier selection. Int. J. Logist. Res. Appl. 2017, 20, 254-275. [CrossRef]

49. Shashi, K.; Singh, R.; Shabani, A. Value-adding practices in food supply chain: Evidence from Indian food industry. Agribusiness 2017, 33, 116-130. [CrossRef] 
50. Baraki, R.R.; Kianfar, F. A fuzzy mathematical model for supplier selection and order allocation considering green vehicle routing problem. Int. J. Logist. Syst. Manag. 2017, 27, 151-163. [CrossRef]

51. Ravi, V.; Shankar, R. Reverse logistics: Insights from sectoral analysis of Indian manufacturing industries. Int. J. Logist. Syst. Manag. 2014, 17, 234-259. [CrossRef]

52. Shashi, K.; Cerchione, R.; Singh, R.; Centobelli, P.; Shabani, A. Food cold chain management: From a structured literature review to a conceptual framework and research agenda. Int. J. Logist. Manag. 2018. [CrossRef]

53. You, X.Y.; You, J.X.; Liu, H.C.; Zhen, L. Group multi-criteria supplier selection using an extended VIKOR method with interval 2-tuple linguistic information. Expert Syst. Appl. 2015, 42, 1906-1916. [CrossRef]

2018 by the authors. Licensee MDPI, Basel, Switzerland. This article is an open access article distributed under the terms and conditions of the Creative Commons Attribution (CC BY) license (http://creativecommons.org/licenses/by/4.0/). 